\title{
Prospective Role of Simvastatin on Wound Healing: Review of the Literature
}

\author{
Nahla Sameh"*, Usama F Aly² ${ }^{2}$, Heba A Abou-Taleb ${ }^{1}$ and Ahmed AH Abdellatif ${ }^{3}$ \\ ${ }^{1}$ Pharmaceutics and Industrial Pharmacy Department, Nahda University, Benisuef, Egypt \\ ${ }^{2}$ Pharmaceutics and Industrial Pharmacy Department, El-Minia University, El-Minia, Egypt \\ ${ }^{3}$ Pharmaceutics and Industrial Pharmacy Department, Al-Azhar University, Assiut, Egypt
}

\begin{abstract}
Background: Wound healing is a normal biological complex and dynamic process of substituting injured and misplaced cellular structures and tissue layers. This complicated development is achieved through four different phases: haemostasis, inflammation, proliferation, and finally remodelling. These four phases must occur in the proper sequence and time frame to achieve successful wound healing. Over years topical antibiotics were applied on wounds but it causes side effects and resistance; that's why it was a necessity to find a new topical wound healing drugs rather than antibiotics.
\end{abstract}

Methods: Literature was searched in NCBI (The National Center for Biotechnology Information Advances Science and Health), Wiley online library, ScienceDirect database using the keywords Simvastatin, wound healing Topical formulation. Articles that seemed suitable based on title and abstract were included. Also, a personal collection of literature on the subject pleiotropic effects of simvastatin, hydrogels, and polymeric nanoparticles was referred.

Results: Beside cholesterol-lowering effect of Simvastatin (SIM), it has many unusual therapeutic modalities for different pathological disorders such as healing bone tissue, cancer cell inhibition, many inflammatory diseases and wound healing. SIM wound healing induction arises from its angiogenesis activity and antibacterial activity. It can interfere with bacterial protein synthesis and inhibits both multiple biosynthetic pathways and cellular processes in bacteria without the conventional antibiotics side effects or fear of bacterial resistance.

Conclusion: This review discusses the wound types and wound healing process, the nanosizing advantage in wound healing, gels and hydrogel characters and the approved application of simvastatin topically to wound healing via promotion of epithelialization and antibacterial activity.

Keywords: Wound; Simvastatin; Healing; Topical formulation

\section{Introduction}

Human skin plays a great protective role, mainly due to stratum corneum layer which make the skin acts as a permeation barrier [1]. Any damage of this layer through wounds or burns lead the skin to lose its protective function and allow the bacteria present on the skin surface to access into body causing infection [2]. Therefore, the wound healing is considered a great issue. Over years many antibiotics was applied topically or even systemically for this purpose. Different antibiotics side effects including nausea, vomiting and irritation beside developing a resistant microorganism made finding new pharmaceutical product for wound healing is a necessity [3]. About $3 \%$ of geriatric people (aged $>60$ years) are suffering from chronic skin wounds which are usually related to vasculopathy or neuropathy like diabetic foot; chronic wounds patients are treated with systemic or topical antimicrobial therapy [4]. Recently; statins showed varied pleiotropic effects other than their lipid lowering activity, so they are now considered a new therapeutic modality for many pathological conditions like sepsis, psoriasis, alopecia, anti-inflammatory, immunomodulatory and wound healing [5]. The anti-inflammatory and immunomodulatory effect occur as a result of depletion of isoprenoids which are intermediate substances during Statins' interference with cholesterol biosynthesis [6]. SIM can help in fracture healing and induction of bone tissue regeneration, and its topical application promotes wound healing in diabetic mice by enhancing angiogenesis and lymph-angiogenesis [7]. A growing number of studies are indicating that SIM can directly influence the growth and virulence of bacterial pathogens [8]. Microbiological studies showed that SIM inhibits Staphylococcus aureus biofilm formation therefore suppress the bacterial growth, and topical application of SIM promote the healing process and cause bacterial clearance of Staphylococcus aureus contaminated wounds [9]. For wound healing purpose, statins are used topically to avoid the systemic side effects like myopathy and liver problem; studies also showed that SIM's high MIC (minimum inhibitory concentration) value cannot be achieved systemically due to its low solubility and poor bioavailability [10]; for this reasons SIM activity for wound healing was limited on topical application only [9]. Nowadays; nanoparticles are receiving considerable attention for the delivery of therapeutic drugs [11]. Nanoparticles are particles with nano-scaled size (less than 1000 $\mathrm{nm})$, and this small size scale make the nanoparticle features with many advantageous characters over the normal bulk material like higher solubility, better release, higher skin permeation and higher intracellular uptake especially of poorly water-soluble/ lipophilic drugs, increasing the drug concentration gradient across the skin with enhanced drug stability [11]. Side effects such as skin irritation can be diminished. Drugs can be directly delivered to the diseases site with slight systemic absorption [12]. Polymeric nanoparticles are prepared from biocompatible and biodegradable polymers in which the drug is entrapped [12]. Nanoparticles could be inserted in gel to ease its topical

*Corresponding author: Nahla Sameh El Sayed, PhD, Assistant Lecturer of Pharmaceutics, Nahda University, Benisuef, Egypt, E-mail: nahla.sameh@nub.edu.eg

Received April 12, 2018; Accepted April 25, 2018; Published April 27, 2018

Citation: Sameh N, Aly UF, Abou-Taleb HA, Abdellatif AAH (2018) Prospective Role of Simvastatin on Wound Healing: Review of the Literature. J Bioequiv Availab 10: 36-42. doi: 10.4172/0975-0851.1000375

Copyright: @ 2018 Sameh N, et al. This is an open-access article distributed under the terms of the Creative Commons Attribution License, which permits unrestricted use, distribution, and reproduction in any medium, provided the original author and source are credited. 
Citation: Sameh N, Aly UF, Abou-Taleb HA, Abdellatif AAH (2018) Prospective Role of Simvastatin on Wound Healing: Review of the Literature. J Bioequiv Availab 10: 36-42. doi: 10.4172/0975-0851.1000375

application. Gels are semisolids pharmaceutical preparation which can act as vehicle for topically applied drugs [13]. Hydrogels are polymeric networks with three-dimensional design and hydrophilic characters [14]. It has provide many advantage like ease in preparation and application, spreadability, possibility for sustained release and presence of reasonable concentration of the active ingredient at the application site over long period [14].

\section{Wounds}

\section{Types of wounds}

Wounds are differed according to its cause, shape, response to medication and patient history; but some types of wounds can be considered as worldwide healthcare problems like diabetic foot ulcer, venous leg ulcers and pressure ulcers [15]. Many classifications can describe the wound types as acute or chronic, open or closed. In open wounds, the skin is broken or removed, and the underlying tissue is exposed to the outside environment while in closed wounds, the skin is unbroken and stays intact, and the underlying tissue is not directly exposed to the outside world [16] (Figure 1).

Open wounds include: abrasions which is shallow wounds at the skins upper layer due to brushing with rough surface, it causes pain and usually no bleeding, incisions: which mainly caused by cutting the skin with sharp objects or after surgical operations, open wounds mast be well monitored and takes a lot of care as it can develop many complication such as infection, inflammation or forming a scar after healing [17]. Diabetic foot ulcer: it's a serious secondary complication of diabetes and it's a cause of complicated mixture of various essential factors, peripheral neuropathy, peripheral arterial diseases, deformity in foot, poor extremity perfusion, and extrinsic causes such as high plantar pressures, about $15 \%-25 \%$ of diabetic patient are in risk in developing diabetic foot ulcer, in developing countries it can be a major cause of morbidity [18].

While closed wounds includes trauma which can damage the internal organs, blood vessels and bones in some cases, and this type is painful and cause skin discoloration to reddish or bluish colour, hematoma which is the wounds causes damage to the small blood vessels, pressure ulcers caused by an external high-pressure force that

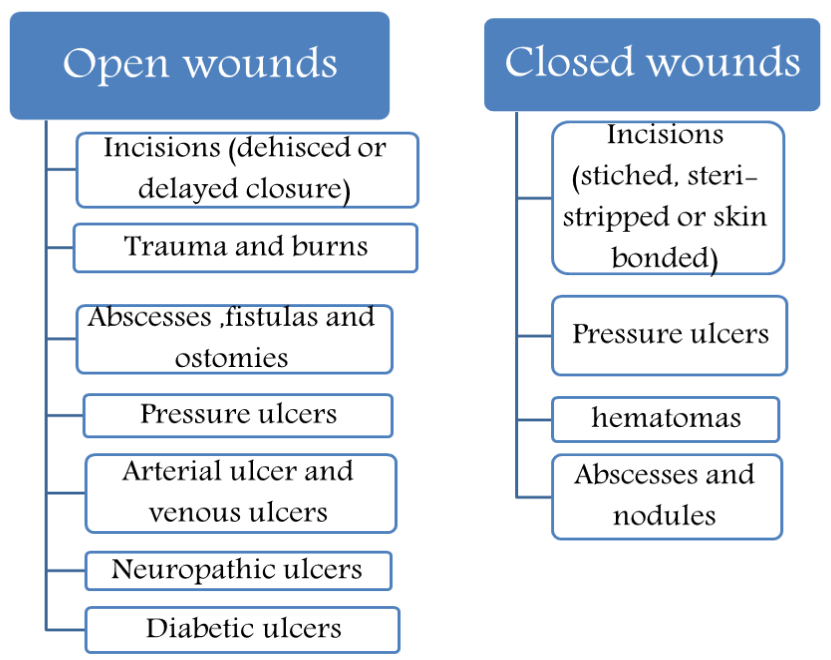

Figure 1: Schematic diagram represents the different types of open and closed wounds. squeezes part of the body between two surfaces. The closed wounds can cause internal tissue damage, bone fracture, nerve damage and internal bleeding.

The wound can be described as chronic when it doesn't heal or responds to treatment indefinite time schedule like most wounds [15]. Chronic wounds with extensive tissue damage become susceptible to inflammation or proliferation and couldn't be able to epithelialize anymore so it does not respond to current treatments, therefore they need special interventions [19]. They are characterized by unresolved inflammation, non-migratory epidermis, damaged fibroblast function and declined angiogenesis with enlarged levels of proteases and bacterial colonization and/or infection. The appearance of chronic wounds due to different reasons like diabetic foot or ulcers is increasing a day after day, reaching epidemic proportions, that's why there is great interest in finding more efficient therapies [20]. However, 44 to $70 \%$ of patients suffering from chronic ulcers still unhealed even after receiving medications or in the clinical trials that lead to FDA approval [21].

\section{Infected wounds}

Once the skin is wounded, the normally present micro-organisms at the skin surface obtain right to enter to the underlying tissues. The wound is classified as contaminated wound according to the state of infection and the microorganisms' replication status. Contamination is characterized by the existence of non-replicating organisms on a wound; while colonization is the existence of replicating microorganisms on the wound without tissue damage [22]. Generally, infection delays the wound healing and lead to chronicity that's why wound care and infection control consider a very important step in wound healing process [23].

Wounds considered one of the biggest clinical problems and are problematic to the patients and the society as well; Wounds are susceptible to bacterial invectives, which interrupt the healing process by inducing inflammation and tissue damage, the clinical benefit of using antimicrobials and antiseptics on open wounds is still controversial. Antibiotics taken systemically or applied topically have not been shown to stimulate wound healing, and the frequent applications of these agents can lead to the appearance of drugresistant microorganisms. On the other hand, topical antiseptics, such as povidone-iodine, chlorhexidine, alcohol, hydrogen peroxide, and silver compounds, show toxicity to host cells, which potentially delays the wound healing. Therefore, there is a necessity to find better wound care modalities, which ideally comprise strategies both to decrease the bacterial contamination in the wound to prevent wound infections and to promote wound healing [24].

\section{Topical wound treatment}

Topical treatment is much preferred than systemic in wound healing as it provides a high concentration of antimicrobial at the infection site with limited potential for systemic toxicity and reducing the development of antibiotic resistance. Topical antimicrobial includes two classes:

- Antiseptics: broad spectrum and can kill or suppress microorganisms but they often cause toxicity to the host tissues.

- Antibiotics: mainly active against specific cell target but there is always a risk of bacterial resistance which can make it ineffective [25].

Most commonly generic products that conventionally used in wound healing Includes: 
Citation: Sameh N, Aly UF, Abou-Taleb HA, Abdellatif AAH (2018) Prospective Role of Simvastatin on Wound Healing: Review of the Literature. J Bioequiv Availab 10: 36-42. doi: 10.4172/0975-0851.1000375

- Honey: which has a good antibacterial activity and improve the healing but the development of honey containing products has been limited by the availability of standardized formula and difficult to have a stable preparation with accepted quality [4].

- Hydrogen peroxide: although it is highly effective against gram positive and negative bacteria till now there is no enough evidence on its advantages on wound healing [4].

- Povidone-iodine: widely used as antiseptic but its activity is greatly influenced by organic matter existence [4].

- Silver: the commonly used antimicrobial especially in burns but it causes skin irritation and discoloration beside systemic distribution and excretion of silver in urine [26].

Generally, during the last century, most of the researchers concerned with the development of the antibiotics marked the decline of many previous medications, but the development of antibioticresistant strains of pathogens has directed to the necessity to find alternative treatments $[27,28]$.

\section{Statins}

Statins family include atorvastatin, fluvastatin, lovastatin, pravastatin, rosuvastatin, simvastatin, and pitavastatin [29,30] (Figure 2).

Statin drugs which inhibit 3-hydroxy-3-methyl-glutaryl-coenzyme A (HMG-CoA) reductase that catalyzes the conversion of HMG-CoA to mevalonate, is a primary rate-limiting step in cholesterol biosynthesis in the body; This action is extremely effective in declining total cholesterol and the low-density lipoprotein level [31]. In addition, statins have been discovered that it can protect from ischemic injury and it can also motivate angiogenesis in animals which is normocholesterolemic [32]. Several mechanisms can explain the useful cardiovascular actions of statins include modulation of endothelial function, antioxidant and anti-inflammatory activity, plaque stabilization, vasculogenesis and effects on thrombosis [33] (Figure 3).

In addition, statins have been reported to cause a decrease in tumor necrotic factor-alpha (TNF- $\alpha$ ), interleukin-6 (IL-6) and malondialdehyde (MDA) along with increase in superoxide dismutase (SOD) that recorded for its antioxidant and cardioprotective actions [33].

Nowadays, because the statins have various pleiotropic effects (non-lipid-modifiable effects) independent of their lipid-lowering actions potentially are considered new unusual therapeutic modality for different pathological disorders such as psoriasis, sepsis, alopecia, wound healing and many inflammatory diseases [34]. Several in vitro and in vivo studies on the influence of statins on bone metabolism

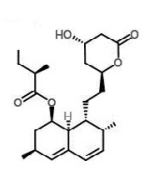

Lovastatin

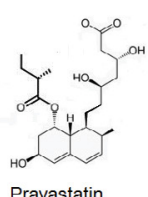

Pravastatin

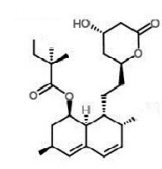

Simvastatin

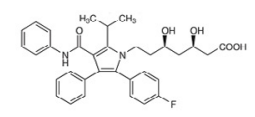

Atorvastatin
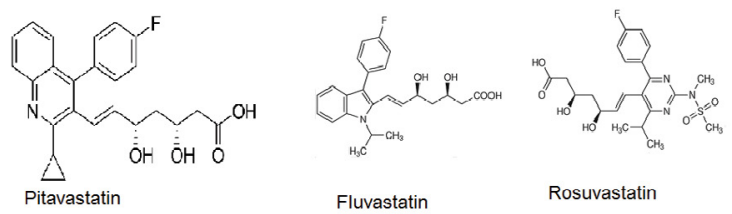

Rosuvastatin

Figure 2: Chemical structure of statins [30].

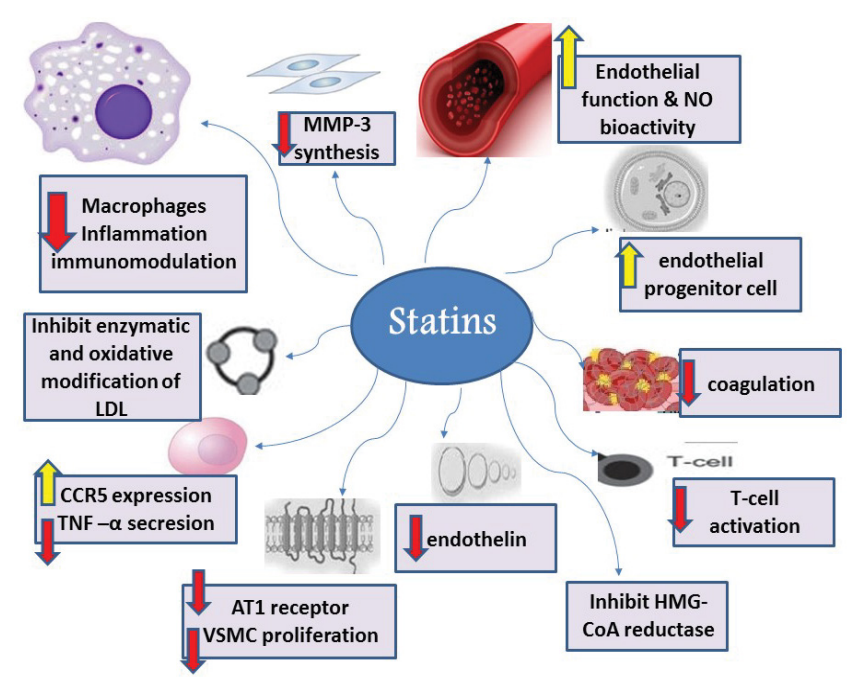

Figure 3: Statin mechanism in protection from ischemic injury and declining total cholesterol and the low-density lipoprotein level.

in long-term usage has been initiated during recent years and the studies confirmed the capability of statins to stimulate expression of bone morphogenetic protein-2 (BMP-2), suppression of osteoclast differentiation and declining of osteoporotic fractures risk [35]. Recent research has confirmed that statins also have immunomodulatory activities due to the interfering with the mediators of the immune system and consequently statins could help in the treatment of many immunological cases which are considered with a Th1 immune response [6].

Statins may prevent the establishment of basal cell carcinoma (BCC) by suppressing the last step in this intracellular pathway, therefore, they can act as a chemopreventive drug in Gorlin's syndrome. Cholesterol depletion from membrane causes the Fas (tumor necrosis factor receptor) activation and apoptosis of keratinocytes. This philosophy may explain the antiproliferative and proapoptotic properties of statins proved by some in vitro studies [6]. Researchers also have identified some evidence on a dichotomous effect of statins with promoting or inhibition to cancer cells [10].

\section{Simvastatin (SIM)}

SIM is a white crystalline powder [36], water-insoluble with estimated water solubility $1.45 \mu \mathrm{g} / \mathrm{mL}$ [37]. Beside cholesterol-lowering effect it was shown that SIM has different therapeutic actions; one of this action is the ability of SIM to increase VEGF (Vascular endothelial growth factor) synthesis and release at the wound site which is a critical step for new blood vessels' production and subsequently ameliorates impaired wound healing in diabetic mice (Figure 4) [38]. SIM can enhance epithelialization and restore the normal skin epidermal barrier via reducing isoprenylation downstream targets of mevalonate and farnesyl pyrophosphate (FPP), decreasing FPP level can promote keratinocyte migration in vitro and epithelialization and wound closure in an ex vivo human culture woundhealing model [32] (Figures 5 and 6).

SIM can induce a significant cell death in a wide range of human tumor cell lines including glioblastoma, astrocytoma, neuroblastoma, lung adenocarcinoma, and breast cancer via decreasing mevalonate formation and downstream farnesyl pyrophosphate (FPP) [39]. FPP inhibits epithelialization and wound healing through the glucocorticoid receptor and its reduction can enhance the epithelialization [40]. SIM also 
Citation: Sameh N, Aly UF, Abou-Taleb HA, Abdellatif AAH (2018) Prospective Role of Simvastatin on Wound Healing: Review of the Literature. J Bioequiv Availab 10: 36-42. doi: 10.4172/0975-0851.1000375

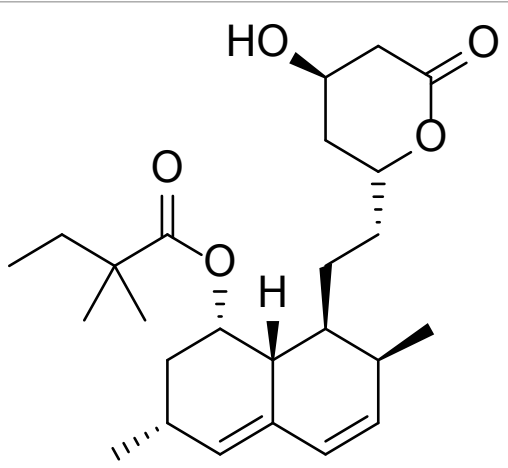

Figure 4: Chemical structure of SIM.

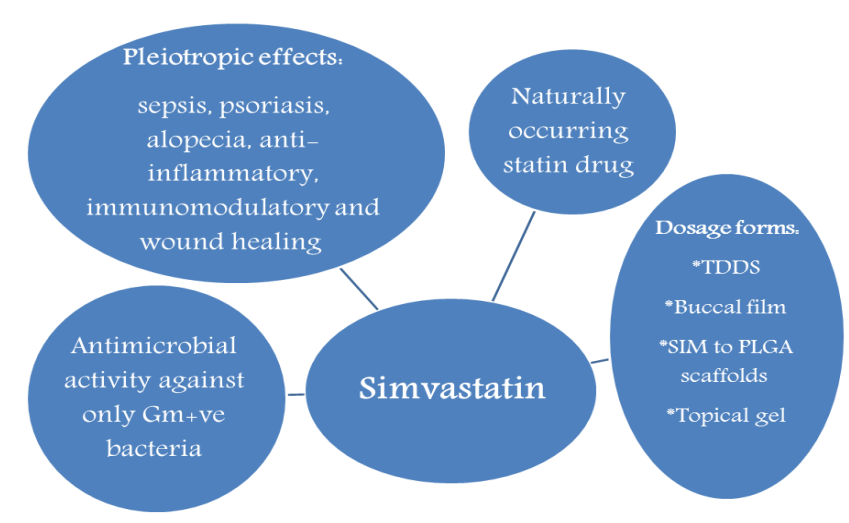

Figure 5: Schematic diagram represent the dosage forms, and the activity of simvastatin for wound healing.

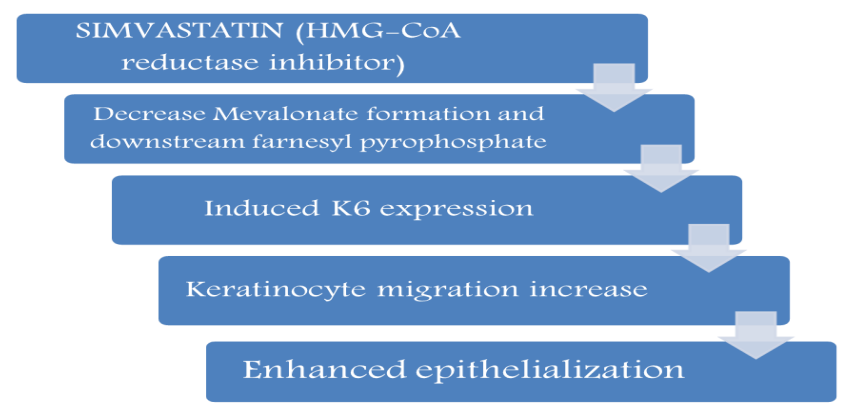

Figure 6: Schematic diagram represent the simvastatin mechanism in enhancing the epithelialization.

showed anabolic effect on bone with stimulation of bone tissue formation, Oxlund and Andreessen found that treatment with SIM at a dose of 20 $\mathrm{mg} / \mathrm{kg}$ orally partially impeded bone loss in female Wistar rats that were subjected to ovariectomy, and also increased cortical bone formation. While Skoglund used higher dose $(120 \mathrm{mg} / \mathrm{kg})$ in studying the effect of statins on bone consolidation in animals. SIM increased the bone callus area and size in animals treated with it. Another study on local application of SIM in $2 \mathrm{mg}$ concentration on the bone defect areas leads to an increase in bone formation and increasing the total amount of new bone without causing a strong immune response [41-43].

Previous researches discovered that among different statin derivatives, SIM was determined as one of the best anti-inflammatory agents and can improved endothelial cell proliferation as well as neovascularization, in a study by Rego et al. it was shown that topical administration of SIM on open skin wounds not only had anti-inflammatory effect, but also reduced bacterial infection of the wound site.

SIM also can work topically as a probable antibacterial agent as it suppresses multiple biosynthetic pathways and cellular processes in bacteria, including selective interference of bacterial protein synthesis. This property seems to improve SIM's capability to inhibit the creation of key MRSA toxins ( $\alpha$-hemolysin and Panton-Valentine leucocidin) that spoil the curative development of the septic skin injuries [9]. SIM inhibition of bacterial protein synthesis is selective for bacterial protein only and don't affect the mammalian mitochondrial protein synthesis [9]. The only statin drug which could inhibit MRSA ATCC 43300 growth with a minimum inhibitory concentration (MIC) value of $32 \mu \mathrm{g} / \mathrm{ml}$. was SIM. and none of the other statin drugs possessed this antibacterial activity with this low (MIC); however, SIM antibacterial activity is restricted to gram positive bacteria only, because the outer membrane in gram negative bacteria act as a barrier and prevent the SIM to enter into gram negative bacteria [9]. Only one single study showed that SIM therapy was related to disturbance of normal proliferation during skin repair due to eliminated VEGF protein release [5]. SIM also prevents Staphylococcus aureus toxin creation and decrease its pre-formed biofilms; it also can decrease the bacterial contents in a mouse model of MRSA skin infection and inhibits the synthesis of bacterial protein and toxin. SIM decreases inflammatory cytokines prompted by MRSA skin infection and it shows a synergistic activity with different topical antimicrobials [9].

\section{Review of SIM different medical uses}

Asai et al. approved in his study that application of SIM topically caused accelerated diabetic wound healing via promotion of angiogenesis and lymphangiogenesis . A preformulation study was made to check the capability of SIM to be adminstrated in the form of transdermal drug delivery system (TDDS) in controlled release manar using polymer like HPMC and Carbopol, to increase its bioavalability and decrease the dosing frequency; and the results showed that SIM can be suitable candidate for TDDS $[44,45]$.

Rashidi et al. developed new administration roots for direct delivery to achieve an optimum concentration of SIM in the bone microenvironment. In this study, the diffusion-controlled release was achieved via making a covalently bonding saponified SIM (sap-sim) to the PLGA in the spinning dope for degradation-controlled release after dissolving SIM (dis-sim) in the membrane casting dope to permit SIM to combine with poly (lactide-co-glycolide) (PLGA) membrane scaffold and this covalent bonding of SIM to PLGA scaffolds could be used as a controlled release scaffold for bone tissue engineering [35]. Wang et al. specified that application of SIM topically at its MIC (minimum inhibitory concentration) against Staphylococcus aureus enhanced the healing and bacterial clearance of S. aureus-contaminated wounds in excisional mice wound model [24]. Rosselli et al., applied SIM gel topically on femurs of rabbit had surgical cavities and the cavities were treated as SIM gel had stimulated the bone repair which promoted an ameliorative effect in the morphological and immunohistochemical markers of bone regeneration. Mandal et al. made a research on the role of SIM in skeletal metastasis breast cancer and reported that SIM acts as an inhibitor of osteolysis in a mouse model of breast cancer skeletal metastasis of human mammary cancer cell MDA-MB-231, which expresses the mutant $\mathrm{p} 53 \mathrm{R} 280 \mathrm{~K}$. Narkhede prepared SIM nanoparticle using Quasi emulsion solvent method to improve the SIM solubility, dissolution and bioavailability, in this method SIM was dissolved in acetone then injected in an aqueous media containing fixed amount of different stabilizer Pluronic F-68 and subsequently stirred on magnetic stirrer to allow acetone evaporation. 
Mangalam et al. improved the SIM solubility and dissolution rate via formulation of nano-particles solid dispersions (NSD) of SIM using poloxamer 188 , a low viscosity grade of (Asafoetida) polymer as solubility enhancing material.

According to BCS (Biopharmaceutics Classification System), SIM categorized as class 2 having low solubility and consequently decreased oral bioavailability (5\%) [46-50]. The only available dosage form of SIM in the market is a tablet in different concentrations of 5,10,20,40 and $80 \mathrm{mg}$ and mainly used to decrease the amount of total cholesterol. Although SIM activity in the field of wound healing, it is not produced as a gel or any topical formulation yet. SIM is poorly water-soluble drug and its half-life are less than 2 hours [51]. Generally, bioavailability is affected by the rate of dissolution which reliant on surface area, solubility, and powder particle wettability. The need to improve the dissolution properties of SIM has been suggested, particles size reduction decrees in drug crystalline till amorphization or formation of met stable polymorphic modification are possible factors which can result in an apparent increase in dissolution rate. SIM can be prepared as nanoparticle to improve its solubility which in turn may improve the bioavailability of the drug. In 2009 Katy Margulis et al formulated SIM as nanoparticles using a novel evaporation technique in which the volatile solvents were evaporated from oil-in-water microemulsion that was spontaneously formed. After incorporation of SIM nanoparticles in tablets, an increase in solubility was established [52]. One year next, Hazem Ali et al. formulated lipid nanoparticles by the insertion of tocotrienol-rich fraction (TRF) into the nanoparticles entrapped the drug within the nano compartments. This formulation was found to have a drug release profile about $20 \%$ in $10 \mathrm{hr}$. followed by a plateau and particle size didn't show any change even after storage for about 6 months. In the 2010 year also Zhiwen Zhang et al. prepared a lipid nanoparticles (SLNs) with a great efficiency encapsulation (greater than 95\%) and the study proved that bioavailability of the drug improved when incorporated into the lipid nanoparticles [53].

Yasasvini et al. loaded SIM-chitosan microparticles on PVA (poly vinyl alcohol) hydrogel matrix system and studied its topical wound healing activity; the prepared formula proved its appropriateness for in vivo application as the optimized formula showed efficiency of the dual controlled release system providing a prolonged effect of drug to support the complete healing process $[54,55]$.

\section{Gels and Hydrogel}

Gels are defined as "semisolid system in which a liquid phase is constrained within a polymeric matrix in which a high degree of physical and chemical cross-linking introduced" [56]. Gels are a relatively newer class of dosage form created by entrapment of large amounts of aqueous or hydroalcoholic liquid in a network of colloidal solid particles. Gel formulations generally provide faster drug release compared with ointments and creams [57]. Although the word "nanoscale" concerns to particle size range from 1 to $100 \mathrm{~nm}$, the range of $50-500 \mathrm{~nm}$ are satisfactory for drug delivery depending on the route of administration as it has an important effect on the drug efficacy [58]. Nanoparticles have comparatively greater intracellular uptake than microparticles. They can penetrate throughout the submucosal layers while the microparticles which are larger in size can't penetrate and remain localized in the epithelial lining [59]. Generally, SIM is nearly insoluble in water and is not well absorbed. Therefore, particle size reduction via preparation of polymeric nanoparticle is one of the methods which are used to improve the dissolution rate of SIM in aqueous media and it may result in better bioavailability [60].
Hydrogels are water-swollen polymeric materials that maintain a distinct three-dimensional structure. They are water washable, nontoxic, biocompatible, without any oily or greasy sensation and can act as a drug carrier for many active ingredients [61]. Hydrogels form a porous network and this porosity can be usually controlled by choosing a definite density of cross-links or by changing the hydrogel swelling affinity, the release of drugs from hydrogels is highly affected by this porosity property and therefore the drug release from hydrogels can be controlled by controlling the diffusion coefficient of drugs through hydrogel matrix [61]. Hydrogels can be classified according to the origin of gelling material if natural origins like chitosan, galantine, and alginate, or hydrogel from synthetic origin like Carbopol [62]. A pilot study was applied to demonstrate the effect of topical SIM based cream for treatment of chronic vascular cutaneous ulcers, according to the study data, the topical administration of statins was very promising but the topical application of SIM based cream wasn't effective in management of chronic vascular leg ulcers in 4 weeks period and the study recommended to find alternative topical delivery [63]. Another study was applied using $2 \%$ SIM gel and the gel was proved to improve the rate of wound closure in laboratory rats with significant antiinflammatory effect and positive influence on re-epithelization and on granulation tissue formation which enhance the wound healing process [43].

\section{Nanotechnology and its Applications}

Nanotechnology can be termed as the synthesis, characterization, examination, and application of nanosized materials for the improvement of science. It gives the materials developed physical, biological and chemical properties because of their nanoscale size. Nanoparticles have some different properties than the bulk form of the same material because of their small size, that's why it offers many new developments in the fields of biomedicine and bio-nanotechnology. Nanotechnology is also employed in medicine for diagnosis, therapeutic drug delivery and the improvement of treatments for many diseases and disorders. Nanotechnology is an extremely powerful technology, which holds a huge promise for the design and improvement of many types of novel products with its potential medical applications on quick disease recognition, treatment, and prevention [43].

A lot of advanced nano-therapies have arisen in the field of wound healing and are presently under clinical investigation. Numerous nanoscale approaches were discovered and used for targeting different stages of wound repair, including nanomaterials.

There are two main types of nanomaterials employed in wound healing:

(1) Nanomaterials that show inherent properties valuable for wound treatment and

(2) Nanomaterials working as delivery vehicles for therapeutic agents [20]. The prolonged nature and related problems of wounds which don't heal have led to the improvement of nanotechnologybased therapies that purpose to make the healing process more easy and simple. A lot of engineered nanotechnologies have been recommended exclusive properties and abundant functions that target specific problems related to wound healing mechanisms [20].

The nanoprecipitation method presents several advantages, in that it is a direct technique, rapid, easy to make besides being appropriate for most of the poorly soluble drugs [64]. In nanoprecipitation method, an organic solvent such as acetone, acetonitrile, methylene chloride, methanol or ethyl acetate was used to dissolve the drug. Then the 
Citation: Sameh N, Aly UF, Abou-Taleb HA, Abdellatif AAH (2018) Prospective Role of Simvastatin on Wound Healing: Review of the Literature. J Bioequiv Availab 10: 36-42. doi: 10.4172/0975-0851.1000375

organic solvent is evaporated via pressure reduction or by continuous stirring. Several factors may influence the particle size such as stabilizer type and concentration and homogenizer speed. Ultrasonication or high-speed homogenization may be used to produce small particle size [65]. Nanoprecipitation technique mainly produces small nanoparticles with narrow distribution.

\section{Conclusion}

Simvastatin showed different activities, illustrated in this review, rather than cholesterol lowering, it is considered a promising candidates for enhancing healing process via improving the angiogenesis process and enhancing the epithelialization, it can suppress the bacterial growth of only gram positive bacteria and this can help in controlling the infected wounds, it can be used topically as hydrogel to accelerate healing without systemic toxicity and to provide higher concentration in the wound site, nanosizing of simvastatin particles can increase its solubility, dissolution, skin permeation and bioavailability due to nanoparticles have greater intracellular uptake than microparticles. The combination of hydrogels with polymeric nanoparticles of drug could be best recommended for effective topical wound healing therapy.

\section{References}

1. Boer M, Duchnik E, Maleszka R, Marchlewicz M (2016) Structural and biophysical characteristics of human skin in maintaining proper epidermal barrier function. Postepy Dermatol Alergol 33: 1-5.

2. Church D, Elsayed S, Reid O, Winston B, Lindsay R (2006) Burn wound infections. Clin Microbiol Rev 19: 403-434.

3. Sevgi M, Toklu A, Vecchio D, Hamblin M (2014) Topical Antimicrobials for Burn Infections: An Update. Recent Pat Antiinfect Drug Discov 8: 161-197.

4. Lipsky BA, Hoey C (2009) Topical antimicrobial therapy for treating chronic wounds. Clin Infect Dis 49: 1541-1549.

5. Farsaei S, Khalili H, Farboud ES (2012) Potential role of statins on wound healing: Review of the literature. Int Wound J 9: 238-247.

6. Forsea DG (2011) Statins and the skin. Ther Pharmacol Clin Toxicol 15: 98104.

7. Rezvanian M, Mohd Amin MCl, Ng SF (2016) Development and physicochemical characterization of alginate composite film loaded with simvastatin as a potential wound dressing. Carbohydr Polym 137: 295-304.

8. Hennessy E, Adams C, Reen FJ, O'Gara F (2016) Is there potential for repurposing statins as novel antimicrobials? Antimicrob Agents Chemother 60: 5111-5121.

9. Thangamani S, Mohammad H, Abushahba MFN, Hamed MI, Sobreira TJP et al. (2015) Exploring simvastatin, an antihyperlipidemic drug, as a potential topical antibacterial agent. Sci Rep 5: 16407

10. Gazzerro P, Proto MC, Gangemi G, Malfitano AM, Ciaglia E, et al. (2012) Pharmacological actions of statins: A critical appraisal in the management of cancer. Pharmacol Rev 641: 102-146.

11. Singh R, LJW (2009) Nanoparticle-based targeted drug delivery. Exp Mol Pathol 86: 215-223.

12. Goyal R, Macri LK, Kaplan HM, Kohn J (2016) Nanoparticles and nanofibers for topical drug delivery. J Control Release 240: 77-92.

13. Chang RK, Raw A, Lionberger R, Yu L (2013) Generic development of topical dermatologic products: Formulation development, process development, and testing of topical dermatologic products. AAPS J 15: 41-52.

14. Caló E, Khutoryanskiy VV (2015) Biomedical applications of hydrogels: A review of patents and commercial products. Eur Polym J 65: 252-267.

15. Wolcott R, Cutting K, Dowd S, Percival S (2010) Types of wounds and infections. Microbiol Wounds 219-232.

16. Ono S, Imai R, Ida Y, Shibata D, Komiya T, et al. (2015) Increased wound pH as an indicator of local wound infection in second degree burns. Burns 41 820-824
17. Rayment EA (2007) Investigation into the proteolytic activity in chronic wound fluid and development of a remediation strategy. Technology.

18. Noor S, Raghav A, Parwez I, Ozair M, Ahmad J (2018) Molecular and culture based assessment of bacterial pathogens in subjects with diabetic foot ulcer Diabetes Metab Syndr Clin Res Rev: 1-5.

19. Castellanos G, Bernabé-García A, Moraleda JM, Nicolás FJ (2017) Amniotic membrane application for the healing of chronic wounds and ulcers. Placenta.

20. Hamdan S, Pastar I, Drakulich S, Dikici E, Tomic-Canic M, et al. (2017) Nanotechnology-driven therapeutic interventions in wound healing: Potential uses and applications. ACS Cent Sci 3:163-175.

21. Embil JM, Nagai MK (2002) Becaplermin: Recombinant platelet derived growth factor, a new treatment for healing diabetic foot ulcers. Expert Opin Biol Ther 2: $211-218$.

22. Guo S, Dipietro LA (2010) Factors affecting wound healing. Journal of Denta Research 859: 219-229.

23. Bessa LJ, Fazii P, Di Giulio M, Cellini L (2015) Bacterial isolates from infected wounds and their antibiotic susceptibility pattern: Some remarks about wound infection. Int Wound J 12: 47-52.

24. Wang CC, Yang PW, Yang SF, Hsieh KP, Tseng SP, et al. (2015) Topical simvastatin promotes healing of Staphylococcus aureus-contaminated cutaneous wounds. Int Wound J: 1-8.

25. http://citeseerx.ist.psu.edu/viewdoc/download?doi=10.1.1.477.733\&rep=rep1\& type $=p d f$

26. Cooper R (2004) A review of the evidence for the use of topical antimicrobial agents in wound care. Worldwide wounds 1-11.

27. Lai HY, Lim YY, Kim KH (2011) Potential dermal wound healing agent in Blechnum orientale Linn; BMC Complement. Altern Med 11: 62.

28. Schachter M (2005) Chemical, pharmacokinetic and pharmacodynamic properties of statins: An update. Fundam Clin Pharmacol 19: 117-125

29. Liao JK, Laufs U (2005) Pleiotropic effects of statins. Annu Rev Pharmaco Toxicol 45: 89-118.

30. Alakhali KM (2014) Validation method for measuring simvastatin in human plasma by HPLC-UV and its application in study simvastatin stability in plasma and working solution. Asian J Pharm Clin Res 7: 50-52.

31. Stojadinovic O, Lebrun E, Pastar I, Kirsner R, Davis SC, et al. (2010) Statins as potential therapeutic agents for healing disorders. Expert Rev Dermatol 5 689-698.

32. Rohilla A, Rohilla S, Kumar A, Khan MU, Deep A (2016) Pleiotropic effects of statins: A boulevard to cardioprotection. Arab J Chem 9: S21-S27.

33. Pella D, Rybar R, Mechirova V (2005) Pleiotropic effects of statins. Acta Cardiol Sin 21: 190-198.

34. Rashidi H, Ellis MJ, Cartmell SH, Chaudhuri JB (2010) Simvastatin release from poly (lactide-co-glycolide) membrane scaffolds. Polymers (Basel) 2: 709718.

35. Ambike AA, Mahadik KR, Paradkar A (2005) Spray-dried amorphous solid dispersions of simvastatin, a low Tg drug: In vitro and in vivo evaluations. Pharm Res 22: 990-998.

36. Rao M, Mandage Y, Khole I, Munjapara G (2011) Characterization of solid dispersions of simvastatin with PVP K30 and poloxamer 188. Indian J Pharm Educ Res 45: 145-152.

37. Rajendran NK, Kumar SSD, Houreld NN, Abrahamse H (2018) A review on nanoparticle based treatment for wound healing. J Drug Deliv Sci Technol 44 421-430.

38. Alizadeh J, Zeki AA, Mirzaei N, Tewary S, Rezaei Moghadam A et al. (2017) Mevalonate cascade inhibition by simvastatin induces the intrinsic apoptosis pathway via depletion of isoprenoids in tumor cells. Sci Rep 7: 1-14.

39. Vukelic S, Stojadinovic O, Pastar I, Vouthounis C, Krzyzanowska A, et al (2010) Farnesyl pyrophosphate inhibits epithelialization and wound healing through the glucocorticoid receptor. J Biol Chem 285: 1980-1988.

40. Vasconcelos JW, Da Silva Leite LM, De Arruda Vasconcelos G, Souto Maior Araujo IM, Ferro LSG (2013) Evaluation of simvastatin in the process of fracture healing in tibiae of rats. Rev Bras Ortop 48:191-195. 
Citation: Sameh N, Aly UF, Abou-Taleb HA, Abdellatif AAH (2018) Prospective Role of Simvastatin on Wound Healing: Review of the Literature. J Bioequiv Availab 10: 36-42. doi: 10.4172/0975-0851.1000375

41. Papadimitriou K, Karkavelas G, Vouros I, Kessopoulou E, Konstantinidis A (2015) Effects of local application of simvastatin on bone regeneration in femoral bone defects in rabbit. J Cranio-Maxillofacial Surg 43: 232-237.

42. Khoshneviszadeh M, Ashkani-Esfahani S, Namazi MR, Noorafshan A, Geramizadeh B, et al. (2014) Topical simvastatin enhances tissue regeneration in full-thickness skin wounds in rat models. Iran J Pharm Res IJPR 13: 263-269.

43. Asai J, Takenaka H, Hirakawa S, Sakabe J, Hagura A, et al. (2012) Topical simvastatin accelerates wound healing in diabetes by enhancing angiogenesis and lymphangiogenesis. Am J Pathol 181: 2217-2224.

44. Zidan AS, Hosny KM, Ahmed OAA, Fahmy UA (2016) Assessment of simvastatin niosomes for pediatric transdermal drug delivery. Drug Deliv 23 : 1536-1549.

45. Rosselli JEGC, Martins DMFS, Martins JL, de Oliveira CRGCM, Fagundes DJ, et al. (2014) The effect of simvastatin on the regeneration of surgical cavities in the femurs of rabbits. Acta Cir Bras 29: 87-92.

46. Mandal CC, Ghosh-Choudhury N, Yoneda T, Choudhury GG, GhoshChoudhury N (2011) Simvastatin prevents skeletal metastasis of breast cancer by an antagonistic interplay between p53 and CD44. J Biol Chem 286: 1131411327.

47. Narkhede K (2015) Devlopement and evaluation of simvastatin nanoparticles using nanosuspension technique. J Pharm Sci Biosci Res 5: 529-534.

48. http://nano-journal.org/dnload/M-Mangalam-N-Punitha-K-Vijayalakshmiand-CSebastian-Antony-Selvan/NANO-JOURNAL-NANV05I06P0139.pdf

49. Jiang T, Han N, Zhao B, Xie Y, Wang S (2012) Enhanced dissolution rate and oral bioavailability of simvastatin nanocrystal prepared by sonoprecipitation. Drug Dev Ind Pharm 38: 1230-1239.

50. Yi YJ, Kim HJ, Jo SK, Kim SG, Song YR, et al. (2014) Comparison of the efficacy and safety profile of morning administration of controlled-release simvastatin versus evening administration of immediate-release simvastatin in chronic kidney disease patients with dyslipidemia. Clin Ther 36: 1182-1190.

51. Margulis-Goshen K, Magdassi S (2009) Formation of simvastatin nanoparticles from microemulsion, nanomedicine nanotechnology. Biol Med 5: 274-281.

52. Ali H, Shirode AB, Sylvester PW, Nazzal S (2010) Preparation, characterization, and anticancer effects of simvastatin-tocotrienol lipid nanoparticles. Int J Pharm 389: 223-231.
53. Zhang Z, Bu H, Gao Z, Huang Y, Gao F, et al. (2010) The characteristics and mechanism of simvastatin loaded lipid nanoparticles to increase oral bioavailability in rats. Int J Pharm 394: 147-153.

54. Yasasvini S, Anusa RS, Vedha Hari BN, Prabhu PC, RamyaDevi D (2017) Topical hydrogel matrix loaded with simvastatin microparticles for enhanced wound healing activity. Mater Sci Eng C 72: 160-167.

55. Basha BN, Prakasam K, Goli D (2011) Formulation and evaluation of gel containing fluconazole-antifungal/reagent. Int J Drug Dev Res 3:109-128.

56. Singla V, Saini S, Joshi B, Rana AC (2012) Emulgel: A new platform for topical drug delivery. Int J Pharma Bio Sci 3: 485-498.

57. Uchechi O, Ogbonna JDN, Attama A (2014) Nanoparticles for dermal and transdermal drug delivery. Appl Nanotechnol Drug Deliv 193-235.

58.https://etd.ohiolink.edu/pg_10?0::NO:10:P10_ACCESSION_ NUM:toledo1271430956

59. Fattahi A, Karimi-Sabet J, Keshavarz A, Golzary A, Rafiee-Tehrani M, et al (2016) Preparation and characterization of simvastatin nanoparticles using rapid expansion of supercritical solution (RESS) with trifluoromethane. J Supercrit Fluids 107: 469-478.

60. J Kopecek (2009) Hydrogels: From soft contact lenses and implants to selfassembled nanomaterials. J Polym Sci Part A Polym Chem 47: 5929-5946.

61. Kopecek J, Yang J (2007) Hydrogels as smart biomaterials. Polym Int 56: 1078-1098.

62. Raposio E, Libondi G, Bertozzi N, Grignaffini E, Grieco MP (2015) Effects of topic simvastatin for the treatment of chronic vascular cutaneous ulcers: A pilot study. J Am Coll Clin Wound Spec 7: 13-18.

63. Pal SL, Jana U, Manna PK, Mohanta GP, Manavalan R (2011) Nanoparticle : An overview of preparation and characterization. J Appl Pharm Sci 1: 228-234

64. Pandya V, Patel J, Patel D (2011) Formulation, optimization and characterization of simvastatin Nanosuspension prepared by nanoprecipitation technique. Der Pharm Lett 3:129-140.

65. Ghaderi S, Ghanbarzadeh, Hamishehkar H (2015) Evaluation of different methods for preparing nanoparticle containing gammaoryzanol for potential use in food fortification. Pharm Sci 20: 130-134. 